\title{
Estimating the need for dental sedation. 4. Using IOSN as a referral tool
}

\author{
M. Goodwin, ${ }^{1}$ P. Coulthard, ${ }^{2}$ I. A. Pretty, ${ }^{3}$ C. Bridgman ${ }^{4}$ L. Gough ${ }^{5}$ \\ and M. 0. Sharif ${ }^{6}$
}
IN BRIEF
- The IOSN tool has demonstrated utility for assessing need within populations and this paper extends its use to an effective means of referring patients for sedation.
- IOSN provides important information on the treatment complexity, medical indications and patient anxiety scores.
- Patient clinical needs cannot be addressed by metrics alone and a clinician's input it always required to interpret the correct clinical pathway.

\begin{abstract}
Objective In this article we report on the use of the IOSN as a referral tool in primary care and the need for sedation in the referred patient population (as determined by the IOSN score). Setting Four centres in the North West of England (primary care) accepting referrals for treatment with the aid of sedation participated in this study. Design A service evaluation. Subjects (materials) and methods The four were provided with IOSN referral forms, operator and patient questionnaires. The centres distributed IOSN forms to referrers as a means of recommending patients for sedation. All patients receiving treatment under sedation (having been referred for treatment through the IOSN form) were asked to complete the patient questionnaire. The individual operator who undertook the treatment under sedation was asked to complete the operator questionnaire. Data were entered into SPSS and the IOSN score noted. Statistical analyses of the data utilised descriptives and comparisons between groups using the Chi Squared test. Results Seventy-eight percent of the patients $(n=140)$ in this study were receiving treatment with sedation appropriately according to the principals of the IOSN. Patients deemed by the IOSN tool to have a low need for sedation were less likely to cancel their appointment if sedation had not been given. The majority of patients were female (70\%) and the majority of operators and patients reported the IOSN forms acceptable for use. Conclusions This study provides support for using the IOSN as a tool for organising sedation referral. The majority of operators and patients reported the IOSN forms acceptable for use.
\end{abstract}

\section{INTRODUCTION}

Referral for treatment with the aid of sedation is a subjective process and some evidence suggests that patients in need of conscious sedation are not being offered this procedure, while others suggest that some sedation services may be demand, rather than needs-led. ${ }^{1}$ The Index of Sedation Need (IOSN) tool was developed to help make the referral process more objective and support clinicians to appropriately offer and utilise sedation services. ${ }^{2,3}$ The development of the IOSN and its use as a health needs assessment tool has been described in previous papers., ${ }^{2,3}$

\footnotetext{
1,2The School of Dentistry, The University of Manchester, Higher Cambridge Street, Manchester, M15 6FH; ${ }^{3 *}$ The Dental Health Unit, School of Dentistry, The University of Manchester, Skelton House, Manchester Science Park, M15 6SH; ${ }^{4}$ NHS Manchester, Parkway 3, Parkway Business Centre, Princess Road, Manchester, M14 7LU; ${ }^{5} \mathrm{NHS}$ Liverpool Headquarters, 1 Arthouse Square, 61-69 Seel Street, Liverpool, L1 4AZ; ${ }^{6}$ NIHR ACF Orthodontics, University of Manchester ${ }^{*}$ Correspondence to: Dr lain Pretty Email: iain.pretty@manchester.ac.uk; Tel: 01612211211

Online article number E9

Refereed Paper - accepted 28 October 2011

DOI: 10.1038/sj.bdj.2012.183

${ }^{\circ}$ British Dental Journal 2012; 212: E9
}

With dental services in England moving to a national commissioning model there is a need to develop robust and dependable referral tools that can operate in the absence of defined local structures and needs-based assessments that were the hallmark of the primary care trusts (PCTs). While it is clear that commissioning of advanced services cannot occur without professional and clinical leadership and guidance, the use of agreed and evidencebased referral tools will assist the transitional process to the new commissioning arrangements.

In this article we report on the use of the IOSN as a referral tool in primary care and the need for sedation in the referred patient population (as determined by the IOSN score). An emphasis is placed on patient and operator perspectives of sedation need in relation to the need as determined by the IOSN score.

\section{METHODS}

Four centres in the North West of England (primary care) accepting referrals for treatment with the aid of sedation participated in this study. They were provided with an IOSN referral form (see article two in this series $^{3}$ ) and an operator (Fig. 1) and patient questionnaire (Fig. 2).

The IOSN form utilises three domains in defining sedation need, these are:

- Treatment complexity

- Medical and behavioural indicators

- Patient anxiety.

The centres were instructed to distribute the IOSN forms to referrers as a means of recommending patients for sedation in addition to their normal referral particulars (for example, radiographs). The IOSN form included a section allowing practitioners to indicate the reason for referral.

All patients receiving treatment under sedation (having been referred for treatment through the IOSN form) were asked to complete the patient questionnaire; this was administered after the patient had demonstrated fitness for discharge using locally derived criteria or a modified Romberg's test. The individual operator who undertook the treatment under sedation was asked to complete the 
operator questionnaire. The participating centres were advised to perform all other procedures as per their normal routine, for example provision of appointments, assessment and treatment visits.

The IOSN referral forms were printed with a blind carbon copy (BCC) sheet, which excluded all personally identifiable data and was detachable (see Fig. 2 in article two of the series ${ }^{3}$ ). Once all the questionnaires were completed they were collated and attached to the BCC of the IOSN and posted back to the study team in Manchester.

The study team received no personally identifiable data, hence the study fell under a service evaluation methodology and was thus exempt from ethical approval requirements.

The data were entered into statistics software SPSS and the IOSN score was noted as well as the corresponding need for sedation. Statistical analyses of the data utilised descriptives and comparisons between groups using the Chi squared test.

\section{RESULTS}

The treatment centres returned a total of 146 referral forms with 140 of them complete and included within the analysis. The demographics of the respondents are shown in Table 1. Table 2 demonstrates the breakdown of sedation need according to the IOSN tool across the 140 returned forms. Table 3 shows the distribution of IOSN domain scores contributing to the overall need.

Patient and operator perspectives of sedation need are demonstrated in Tables 4 and 5. In these tables the patients have been split according to whether they would be referred for sedation in keeping with the principals of the IOSN or not (sedation need - IOSN scores relating to minimal and moderate need, no sedation need IOSN scores relating to high and very high need). Eighty-five percent of patients that needed sedation according to the IOSN tool reported that they may well have cancelled their appointment without the offer of sedation; for patients deemed not to need sedation this figure fell to 43\%. Fisher's exact test demonstrated a statistical difference in the patient response, agreeing or disagreeing, according to sedation need ( $p<0.05$ ).

Seventeen percent of patients deemed not to need sedation reported that they

\begin{tabular}{|c|c|c|c|}
\hline & Agree & Disagree & Unsure \\
\hline \multicolumn{4}{|l|}{ Thinking about the treatment you provided today: } \\
\hline \multicolumn{4}{|l|}{$\begin{array}{l}\text { I could not have performed this treatment on this patient } \\
\text { without sedation }\end{array}$} \\
\hline \multicolumn{4}{|l|}{$\begin{array}{l}\text { I could have performed the treatment but it would have } \\
\text { taken considerably longer }\end{array}$} \\
\hline \multicolumn{4}{|l|}{$\begin{array}{l}\text { I could have provided the treatment without sedation but it } \\
\text { would have been an unpleasant experience for the patient }\end{array}$} \\
\hline \multicolumn{4}{|l|}{ If I was the patient I would have had sedation today } \\
\hline \multicolumn{4}{|l|}{$\begin{array}{l}\text { I believe there would have been a risk of non-attendance } \\
\text { had this patient not been offered sedation }\end{array}$} \\
\hline \multicolumn{4}{|l|}{ Thinking about the IOSN form: } \\
\hline \multicolumn{4}{|l|}{ The medical history detail was suitable for my use } \\
\hline \multicolumn{4}{|l|}{ The treatment complexity score was accurate } \\
\hline \multicolumn{4}{|l|}{ The anxiety section was completed correctly } \\
\hline The treatment offered today: & \multicolumn{3}{|c|}{ Please write response } \\
\hline \multicolumn{4}{|l|}{ Anxiety management offered (IV, RA, CBT, other) } \\
\hline \multicolumn{4}{|l|}{ Dose used } \\
\hline \multicolumn{4}{|l|}{$\begin{array}{l}\text { Dental treatment undertaken with brief details (that is, } \\
\text { surgical extraction of lower } 8 \text {, moderate bone removal) }\end{array}$} \\
\hline \multicolumn{4}{|l|}{ Time taken to complete treatment (minutes) } \\
\hline Free comments on the patient, form and treatment & $\begin{array}{l}\text { Please a } \\
\text { treatme } \\
\text { feel will }\end{array}$ & $\begin{array}{l}\text { further info } \\
\text { tion and pa } \\
\text { ful. }\end{array}$ & $\begin{array}{l}\text { tion on the } \\
\text { it that you }\end{array}$ \\
\hline
\end{tabular}

\section{Fig. 1 Operator questionnaire}

\begin{tabular}{l|l|l|l}
\hline & Yes & No & Don't know \\
\hline Thinking about the treatment you had today: & & & \\
\hline I could not have had this treatment without sedation & & & \\
\hline $\begin{array}{l}\text { Without the offer of sedation, I may have cancelled or not } \\
\text { attended this appointment }\end{array}$ & & & \\
\hline I asked for this treatment to be provided under sedation & & & \\
\hline $\begin{array}{l}\text { My dentist suggested that I have this treatment } \\
\text { under sedation }\end{array}$ & & & \\
\hline
\end{tabular}

Thinking about a year from now:

I would ask for sedation again in the future for this type of treatment

I would ask for sedation again for any form of dental treatment

Thinking about your sedation use in the past:

I always have sedation for dental treatment

I don't usually go to a dentist because I am not able to get sedation

I don't usually have sedation but my treatment was

complex today

I have failed to attend appointments in the past as I have not been offered sedation

Thinking about the IOSN form that you completed (copy on the back of this sheet):

\begin{tabular}{|l|l|l|l}
\hline I found the form easy to complete & & & \\
\hline I was happy to complete the form & & & \\
\hline I needed some help to complete the form & & & \\
\hline
\end{tabular}

Fig. 2 Patient questionnaire 


\begin{tabular}{l|l|l}
\hline Table 1 Demographics of respondents $(\boldsymbol{n}=\mathbf{1 4 0})$ & Mean age (SD) \\
\hline Gender & Number & $42(14.9)$ \\
\hline Male & 39 & $44(15.4)$ \\
\hline Female & 101 & $43(15.2)$
\end{tabular}

\begin{tabular}{|l|l|l|}
\hline Table $\mathbf{2}$ The need for sedation within the population of four centres \\
\hline Sedation need as indicated by IOSN score & Frequency & Percentage \\
\hline Minimal & 4 & 3 \\
\hline Moderate & 38 & 27 \\
\hline High & 97 & 69 \\
\hline Very high & 1 & 1 \\
\hline Those who would have had sedation according to IOSN tool & $70 \%$ \\
\hline
\end{tabular}

\begin{tabular}{|c|c|c|c|c|}
\hline Sedation need & Rank & $\begin{array}{l}\text { Treatment } \\
\text { complexity }\end{array}$ & Medical score & Anxiety score \\
\hline \multirow{4}{*}{$\begin{array}{l}\text { Minimal } \\
1\end{array}$} & 1 & 3 & 1 & 4 \\
\hline & 2 & 1 & 3 & 0 \\
\hline & 3 & 0 & 0 & 0 \\
\hline & 4 & 0 & 0 & 0 \\
\hline \multirow{4}{*}{$\begin{array}{l}\text { Moderate } \\
2\end{array}$} & 1 & 22 & 29 & 6 \\
\hline & 2 & 11 & 9 & 6 \\
\hline & 3 & 5 & 0 & 7 \\
\hline & 4 & 0 & 0 & $19^{*}$ \\
\hline \multirow{4}{*}{$\begin{array}{l}\text { High } \\
3\end{array}$} & 1 & 24 & 37 & 0 \\
\hline & 2 & 55 & 36 & 6 \\
\hline & 3 & 18 & 20 & 16 \\
\hline & 4 & 0 & 4 & 75 \\
\hline \multirow{4}{*}{$\begin{array}{l}\text { Very high } \\
4\end{array}$} & 1 & 0 & 0 & 0 \\
\hline & 2 & 0 & 0 & 0 \\
\hline & 3 & 1 & 1 & 0 \\
\hline & 4 & 0 & 0 & 1 \\
\hline
\end{tabular}

could have tolerated treatment without it. Despite this, $100 \%$ of these patients reported that for the same type of treatment they would ask for sedation again.

Operators reported that in 75\% of the patient cases seen and judged to need sedation according to the IOSN, they could not have performed the treatment without sedation. In comparison to this, operators reported that in only $45 \%$ of patient cases where the IOSN deemed that the patient did not need sedation, that they could not have performed the treatment without sedation. Analysis demonstrates a significant difference in operator response to this question depending on whether sedation was needed or not (Fishers exact test, $\mathrm{p}<0.05)$. Question three also showed a significant difference according to chi-square $\left(\chi^{2}(1)=8.834, p<0.05\right)$ with a higher proportion of operators believing they could have performed the treatment without sedation, although it would have been unpleasant for the patient within the group considered to have no need for sedation.
Tables 6 and 7 reveal patient and operator responses to the use and suitability of the IOSN forms. No further information was provided by the respondents in relation to the tools utility.

\section{DISCUSSION}

Throughout the four treatment centres a higher proportion of female patients to male was apparent (overall 72:28); this corresponds with the finding that females are more likely to need sedation in relation to their dental treatment (reported in paper two of this series ${ }^{3}$ ).

Analysis of the data showed that $70 \%$ of patients receiving treatment at the sedation centres studied would have been referred for sedation if the IOSN tool were used (Table 3). Conversely, 30\% of patients were deemed not to need sedation. However, due to the large number of 'high anxiety' patients who appear in the moderate need for sedation section according to the IOSN tool (Table 3) and the fact that 13 of these patients (34\%) had a modified dental anxiety score (MDAS) of 24/25, indicative of dental phobia, it is thus plausible that these referrals were appropriate. To address this, the authors recommend that the decision to refer a patient when a score of rank 4 is present in the anxiety domain but the patient does not automatically qualify for referral should be based on an individual's MDAS in conjunction with treatment complexity. Indeed, if it is assumed that if all the patients in this study population with an MDAS of 24 and 25 were referred for sedation then the IOSN tool would concur with the recommendation for treatment with sedation in 78\% of cases (Table 8).

Analysis of both patient and operator perspectives demonstrated a number of significant differences between those that the IOSN tool determined required sedation and those that did not. Patients deemed by the IOSN tool to have a low need for sedation were less likely to cancel their appointment if sedation had not been offered when compared to those who had a high need for sedation (Table 4). This concept is reinforced by the significant difference observed in operator responses, which indicated just under half (45\%) of the operators whose patients had a low need for sedation believed this procedure was required to carry out their treatment, compared to operators who reported that in 


\begin{tabular}{|c|c|c|c|c|c|c|}
\hline \multirow{3}{*}{ Patient questions } & \multicolumn{6}{|c|}{ Sedation need } \\
\hline & \multicolumn{3}{|c|}{ No need for sedation } & \multicolumn{3}{|c|}{ Need for sedation } \\
\hline & Agree & Disagree & $\begin{array}{l}\text { Don't } \\
\text { know }\end{array}$ & Agree & Disagree & $\begin{array}{l}\text { Don't } \\
\text { know }\end{array}$ \\
\hline $\begin{array}{l}\text { I could not have had this } \\
\text { treatment without sedation }\end{array}$ & $72 \%$ & $17 \%$ & $10 \%$ & $81 \%$ & $14 \%$ & $5 \%$ \\
\hline $\begin{array}{l}\text { Without the offer of sedation, } \\
\text { I may have cancelled or not } \\
\text { attended this appointment }\end{array}$ & $43 \%$ & $21 \%$ & $36 \%$ & $85 \%$ & $12 \%$ & $3 \%$ \\
\hline $\begin{array}{l}\text { I asked for this treatment to } \\
\text { be provided under sedation }\end{array}$ & $63 \%$ & $29 \%$ & $8 \%$ & $87 \%$ & $12 \%$ & $1 \%$ \\
\hline $\begin{array}{l}\text { My dentist suggested that I } \\
\text { have this treatment } \\
\text { under sedation }\end{array}$ & $74 \%$ & $26 \%$ & $0 \%$ & $49 \%$ & $49 \%$ & $2 \%$ \\
\hline $\begin{array}{l}\text { I would ask for sedation again } \\
\text { in the future for this type } \\
\text { of treatment }\end{array}$ & $100 \%$ & $0 \%$ & $0 \%$ & $99 \%$ & $1 \%$ & $0 \%$ \\
\hline
\end{tabular}

\begin{tabular}{|c|c|c|c|c|c|c|}
\hline \multirow{3}{*}{ Operator questions } & \multicolumn{6}{|c|}{ Sedation need } \\
\hline & \multicolumn{3}{|c|}{ No need for sedation } & \multicolumn{3}{|c|}{ Need for sedation } \\
\hline & Agree & Disagree & $\begin{array}{l}\text { Don't } \\
\text { know }\end{array}$ & Agree & Disagree & $\begin{array}{l}\text { Don't } \\
\text { know }\end{array}$ \\
\hline $\begin{array}{l}\text { I could not have performed } \\
\text { this treatment on this patient } \\
\text { without sedation }\end{array}$ & $45 \%$ & $31 \%$ & $24 \%$ & $75 \%$ & $16 \%$ & $9 \%$ \\
\hline $\begin{array}{l}\text { I could have performed the } \\
\text { treatment but it would have } \\
\text { taken considerably longer }\end{array}$ & $59 \%$ & $33 \%$ & $7 \%$ & $43 \%$ & $47 \%$ & $10 \%$ \\
\hline $\begin{array}{l}\text { I could have provided the } \\
\text { treatment without sedation } \\
\text { but it would have been an } \\
\text { unpleasant experience for } \\
\text { the patient }\end{array}$ & $79 \%$ & $17 \%$ & $4 \%$ & $44 \%$ & $49 \%$ & $7 \%$ \\
\hline $\begin{array}{l}\text { If I was the patient I would } \\
\text { have had sedation today }\end{array}$ & $67 \%$ & $19 \%$ & $14 \%$ & $67 \%$ & $23 \%$ & $11 \%$ \\
\hline $\begin{array}{l}\text { I believe there would have } \\
\text { been a risk of non-attendance } \\
\text { had this patient not been } \\
\text { offered sedation }\end{array}$ & $43 \%$ & $21 \%$ & $36 \%$ & $76 \%$ & $13 \%$ & $11 \%$ \\
\hline
\end{tabular}

\section{Table 6 Patient opinions of IOSN forms}

\begin{tabular}{|l|l|l|l|l}
\hline Opinion & Yes (\%) & No (\%) & Don't know (\%) & Missing (\%) \\
\hline I found the form easy to complete & $100(71)$ & $29(21)$ & $1(1)$ & $10(7)$ \\
\hline I was happy to complete the form & $120(86)$ & $13(9)$ & $0(0)$ & $7(5)$ \\
\hline I needed some help to complete the form & $51(36)$ & $81(58)$ & $0(0)$ & $8(6)$ \\
\hline
\end{tabular}

Table 7 Operator opinions of IOSN forms

\begin{tabular}{|l|l|l|l|l|}
\hline Opinion & Yes (\%) & No (\%) & Don't know (\%) & Missing (\%) \\
\hline $\begin{array}{l}\text { The medical history detail was suitable } \\
\text { for my use }\end{array}$ & $115(82)$ & $21(15)$ & $0(0)$ & $4(3)$ \\
\hline $\begin{array}{l}\text { The treatment complexity score } \\
\text { was accurate }\end{array}$ & $114(81)$ & $19(14)$ & $0(0)$ & $7(5)$ \\
\hline $\begin{array}{l}\text { The anxiety section was completed } \\
\text { correctly }\end{array}$ & $129(92)$ & $7(5)$ & $1(1)$ & $3(2)$ \\
\hline
\end{tabular}

$75 \%$ of the patient cases seen and judged to need sedation according to the IOSN, that this treatment was indeed required. This suggests that over half of the patients which the IOSN deemed a low need for sedation may not have required this procedure at all.

Interestingly there was no difference in patient response between the groups regarding the option of having sedation at another time; almost all participants indicated that after receiving sedation they would ask for it again for the same type of treatment. This demonstrates a compounding factor for the importance of such a tool, as it is important not only to determine those that need sedation but conversely those that do not, to ensure the sedation service is not demand-led. This study has shown that despite $17 \%$ of participants indicating they could have had treatment without sedation, all went on to state they would ask for sedation again for the same procedure. It is therefore important that a tool such as IOSN is used to reflect not only those that need sedation but also to prevent a number of patients becoming dependent on a process they do not require. This is vital not only from a cost perspective but also to create balanced and suitable allocation of sedation services for patients.

The information provided on the IOSN forms in relation to the three domains (treatment complexity, medical history and anxiety score) was deemed to be appropriate by $81 \%$ of operators. In terms of patient acceptability, $71 \%$ of patients found the form easy to complete and $86 \%$ of them were happy to complete the form. Six percent of patients reported needing help filling forms, which could be related to many factors such as patients not having reading glasses with them or requiring help with translations. These figures suggest that the IOSN referral process is acceptable according to both operators and patients.

\section{CONCLUSION}

This paper is the fourth and final in a series that consider the need for dental sedation among patients. ${ }^{2}$ Paper two examined the results of a study which involved over 600 completed IOSN forms in order to establish the number of attending patients who would need sedation. ${ }^{3}$ It was determined, on a simplistic level, that 5\% of attending 
Table 8 The need for sedation within the population of four centres if patients with MDAS scores of $24 / 25$ were referred for sedation

\begin{tabular}{l|l|l}
\hline Sedation need as indicated by IOSN score & Frequency & Percentage \\
\hline Minimal & 4 & 3 \\
\hline Moderate & 25 & 18 \\
\hline High & 97 & 68 \\
\hline Very high & 14 & 10 \\
\hline Patients referred for sedation & & $78 \%$
\end{tabular}

patients would at some time need sedation services. This figure was used alongside a large scale study in paper three ${ }^{4}$ to determine the number of non-attendees who may benefit from sedation, as their lack of attendance was due partly to anxiety. This combination showed that the sedation need throughout the entire population may increase to $6.9 \%$. The IOSN tool provided figures in line with internationally reported values ${ }^{5-8}$ and has been further validated within this study through its concurrence with $78 \%$ of sedation referrals and by the fact that of the $22 \%$ who would not have received sedation under the IOSN, over half of the operators stated they could have performed the treatment without it.

The IOSN tool is to be used as an aid to sedation referral and not a definitive verdict, as there will always be a number of patients who may require sedation under exceptional circumstances. ${ }^{9,10}$ Therefore the final judgement as to the need for sedation should be from both clinician and patient. However, the use of the IOSN tool could aid in this process and prevent a demand-led service. It should also be noted that sedation is only one technique which can be utilised to provide dental treatment in circumstances where either due to anxiety, treatment complexity or medical indicators (or a combination of these) a patient requires an alternative intervention. For patients where anxiety is a major contributing factor and a patient does not require urgent dental treatment, it is possible behavioural management or other psychological interventions may produce a long term effect on a patient, showing a reduction in anxiety and increasing dental attendance. ${ }^{11}$

\section{NOTES}

A copy of the IOSN form is available to download from www.dental-referrals.org. Simply select 'forms and tools' from the homepage, then follow the 'forms and resources' to referral forms. A Word version is made available for commissioning bodies to make alterations to the form as required.

Mr Mohammad O Sharif is funded from an in practice fellowship award from the NIHR. We are very grateful to the practices that took park and the Clinical Reference Group chaired by Dr Lesley Longman who provided helpful advice on the protocol for this study.

1. Coulthard P, Horner K, Sloan P, Theaker E. Master dentistry volume 1: oral and maxillofacial surgery, radiology, pathology and oral medicine. Edinburgh: Churchill Livingstone, 2008.

2. Coulthard $P$, Bridgman $C M$, Gough L, Longman L Pretty I A, Jenner T. Estimating the need for dental sedation. 1. The Indicator of Sedation Need (IOSN) a novel assessment tool. Br Dent J 2011; 211: E10.

3. Pretty | $\mathrm{A}$, Goodwin $\mathrm{M}$, Coulthard $\mathrm{P}$ et al. Estimating the need for dental sedation. 2. Using IOSN as a health needs assessment tool. Br Dent J 2011; 211: E11.

4. Goodwin M, Pretty I A. Estimating the need for dental sedation. 3: Analysis of factors contributing to non-attendance for dental treatment in the general population, across 12 English primary care trusts. Br Dent J 2011; 211: 599-603.

5. Boyle C A, Newton T, Milgrom P. Who is referred for sedation for dentistry and why? Br Dent J 2009: 206: E12.

6. Chanpong B, Haas D A, Locker D. Need and demand for sedation or general anesthesia in dentistry: a national survey of the Canadian population. Anesth Prog 2005; 52: 3-11.

7. Dionne R A, Gordon S M, McCullagh L M, Phero J C Assessing the need for anesthesia and sedation in the general population. J Am Dent Assoc 1998; 129: 167-173.

8. Woolley S M. An audit of referrals to a secondary care sedation unit. Br Dent J 2009; 206: E10.

9. Department of Health. A conscious decision. A review of the use of general anaesthesia and conscious sedation in primary dental care. London: Department of Health; 2000

10. Blain K M, Hill FJ. The use of inhalational sedation and local anaesthesia as an alternative to general anaesthesia for dental extractions in children. Br Dent J 1998; 184: 608-611.

11. Kvale G, Berggren U, Milgrom P. Dental fear in adults: a meta-analysis of behavioural interventions. Community Dent Oral Epidemio/ 2004; 32: 250-264. 